\title{
Experimental Examination of Mechanical Analysis on Pandanus Odorifer Fiber Reinforced Polymer Composites
}

\author{
Jothiraj Palaniappan, Vignesh S, Winowlin Jappes J T
}

\begin{abstract}
The advancement in the polymeric science and materials have led to the conglomeration of the both entities to a different wide variant of composite materials. The advancement have made it very clear with the enunciation of the various composites with varied matrix and binders. The objective of this work is to prepare a low weight composite material with natural fiber for packaging applications. Pandanus odorifer with the low density polyester resin composites were chosen and prepared and characterized for various mechanical properties such as tensile and impact test to ensure its endurance in the applications.
\end{abstract}

Keywords: Polymeric Composite, Mechanical Studies and Pandanus Odorifer.

\section{INTRODUCTION}

The fiber reinforced polymeric composite have made a vibrant materials substitution in all aspect of material science whereby it have made it clear to the way of the various materials with the desired properties of structures. Even to the cause of failure and its redundancy is evaluated in terms of vibration analysis [1]. The addition of the polymeric composite with the inclusion of the fiber matrix have widely influenced the tensile property of the materials. The uniqueness of the materials are rendered by the independent tensile characteristics of the matrix materials [2]. To improve the mechanical strength of the fiber thereby to inculcate the higher strength to the mass ratio is elucidated with the chemical treatment which includes the alkaline and saline treatment. The alkaline and saline treatment have led to the significant improvement and mechanical strength of the materials of the fiber. Even the impact behavior of the materials have been effected due cause of treatment in lower residual stresses [3]. The advancement of the usage of the desired composite in the high temperature application is studied via the basalt as the filler materials and the analysis of the materials strength studies reporting the higher tensile strength [4]. The improved mechanical strength of the carbon

Revised Manuscript Received on December 15, 2019.

* Correspondence Author

Jothiraj Palaniappan*, Department of Mechanical Engineering, Kalasalingam Academy of Research and Education, Virudhunagar , India. Email: jothiraj@klu.ac.in

Vignesh S, Department of Mechanical Engineering, Kalasalingam Academy of Research and Education, Virudhunagar , India. Email: vignesh@klu.ac.in

Winowlin Jappes J T, Department of Mechanical Engineering, Kalasalingam Academy of Research and Education, Virudhunagar ,

India. Email: winowlin@klu.ac.in fibers increased by $66 \%$ and the flexural modulus by $72 \%$, while inter laminar shear strength by $25 \%$ [5]. The overview of all those mechanical strength of the natural fiber is elucidated in the paper. [6,7]. The investigation of the mechanical properties of the developed natural fiber to include the biodegradability materials enhancing the fiber composite structural stabilities [8]. The mechanical properties of the hemp fiber polymeric thermoplastic polyurethane composite was studied and its flexural strength was enhanced by $193.2 \%$.[9]. The inherited effect of the mechanical and chemical properties of the red mud assisted polyester epoxy bamboo was studied emphasizing the use of $15 \mathrm{wt} \%$ filler offered improved result by $10 \mathrm{wt} \%$ of the filler content [10]. Even the studies of Okra fiber has also elucidated the improved strength [11].

\section{MATERIALS AND METHODS}

Pandanus Odorifer a higher monopolized species of Pandanacenae family was procured from the local vendors. It is commonly known as screw-pine. Leaves are glucose, 40-70 cm. long. The Resin-Isophthalic polyester resin which is thermo set, capable of being cured from a liquid or solid state when subjected to optimum condition is used as accelerator. Polyester resins, are simply as 'polyesters '. Styrene is a viscous pale colored liquid of polyester base. The addition of styrene in amounts of up to $50 \%$ aids in reducing the viscosity of the resin making it more lean for the molding aspects.. For this research work, the isophthalic resin used as matrix purchased from $\mathrm{M} / \mathrm{s}$.vasavibala resin pvt.Ltd, Chennai, tamilnadu, India. Curing is usually regulated by heat, pressure and by addition of various curing agents at room temperature. Epoxies and polyesters react to from an interconnect structure without formulation of any volatile by-product. Epoxies and polyesters can be cured at atmospheric pressures and also at ambient temperature.

Cobalt Napthanate is used for activation of the process and to accelerate the resin at room temperature. They are widely employed catalyst because they are soluble in the non-polar sub states, such as the alky resins or linseed oil as the napthanates mixtures helps to confer high solubility and it is low cost. Compounds containing in the accelerator are manganese and iron. Catalyst-Methyl Ethyl Ketone Peroxide is used to initiate the polymerization and activate the process. 


\section{Experimental Examination of Mechanical Analysis on Pandanus Odorifer Fiber Reinforced Polymer Composites}

(MEKP) organic peroxide, a highly explosive similar to acetone peroxide. For a combination of the matrix 100 grams of resin with $1.5 \mathrm{ml}$ of Methyl ethyl ketone peroxide (MEKP) and cobalt naphthenate have been used as accelerator and catalyst for room temperature curing.

Table- I: Properties of Resin

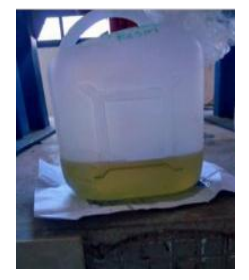

Fig.1.Isophtha lic resin

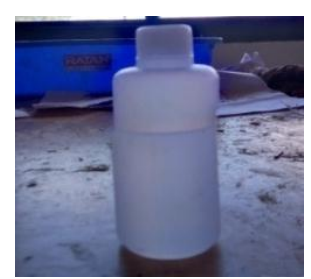

Fig 2. Accelerator

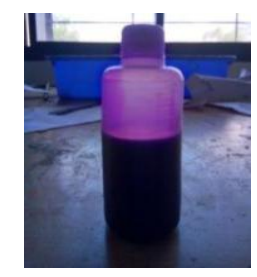

Fig 3. Catalyst

\begin{tabular}{|c|c|c|c|c|c|c|c|}
\hline $\begin{array}{c}\text { Parti } \\
\text { cular } \\
\text { S }\end{array}$ & $\begin{array}{l}\text { Visc } \\
\text { osity }\end{array}$ & $\begin{array}{c}\text { Densi } \\
\text { ty }\end{array}$ & $\begin{array}{c}\text { Elon } \\
\text { gatio } \\
\mathrm{n} \text { at } \\
\text { break }\end{array}$ & $\begin{array}{l}\text { Tensi } \\
\text { le } \\
\text { stren } \\
\text { gth }\end{array}$ & $\begin{array}{l}\text { Youn } \\
\text { g's } \\
\text { modu } \\
\text { lus }\end{array}$ & $\begin{array}{c}\text { Flexu } \\
\text { ral } \\
\text { stren } \\
\text { gth }\end{array}$ & $\begin{array}{c}\text { Flexu } \\
\text { ral } \\
\text { modu } \\
\text { lus }\end{array}$ \\
\hline Valu & 650 & 1.15 & 4.8 & $41 \pm 1$. & $968 \pm$ & $61 \pm 2$ & 2461 \\
\hline es & $(c P s)$ & $(\mathrm{g} / \mathrm{cm}$ & $(\%)$ & 6 & 4.07 & 26 & \pm 2.22 \\
\hline (Unit & & 3 & & $(\mathrm{MPa}$ & $(M P a$ & $(\mathrm{MPa}$ & $(\mathrm{MPa}$ \\
\hline s) & & & & ) & ) & ) & ) \\
\hline
\end{tabular}

The fibers where randomly aligned, washed with dry air. Those fibers were cut into various desired sizes of $3 \mathrm{~mm}, 4 \mathrm{~mm}$ and $5 \mathrm{~mm}$. The mould $(300 \mathrm{~mm} * 125 \mathrm{~mm} * 3.2 \mathrm{~mm})$ was cleaned and polishing wax was applied for the removable of the specimen without any adhesive pull off. Isophathalic polyester resin were mixed with $1.5 \mathrm{wt} \%$ cobalt naphthenate (accelerator) and $1.5 \mathrm{wt} \%$ methyl ethyl ketone peroxide was made tocuring agent, The Fig.1,2,3 depicts the images of resin, accelerator and catalyst. The treated fibers were arranged in the mould in the form of mat and pressed. The casing is put under load for about 3 to 4 hours for proper curing at room temperature. This is predominantly used manual mixing procedure between the fiber and matrix. After 3 to 4 hours the mould is removed from compression machine. Shown in Fig 4 in the molding machine and Fig 5 is the molded composite compound structure.

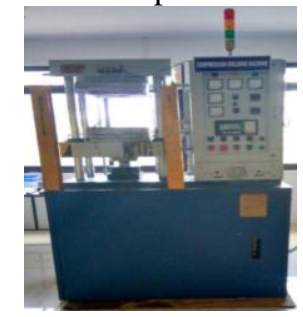

Fig 4. Compression molding machine

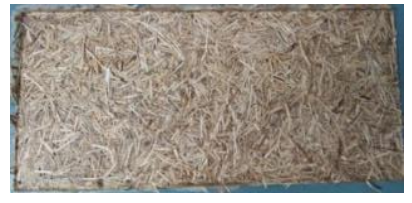

Fig.5. Fabricated composite sample

\section{RESULTS AND DISCUSSION}

\section{A. Tensile Test}

The mechanical testing enables the critic to study the prompt the materials and its relevance to the usage in substitution aspect of the material. The Ultimate strength often refers to the maximum stress that a material can withstand to its

breakage of failure points.. Tensile strength is opposite to compressive strength. The UTS is usually found by performing a tensile test and recording the stress versus strain; the highest point of the stress strain curve is the UTS. In the resting the materials or specimen are continuously pulled to its breakage, to find the tensile strength of the fabricated composites in a UTM. The cross head speed of $5 \mathrm{~mm} / \mathrm{min}$ is maintained according to the ASTM D 638.Fig.6 shows the Universal Tensile testing machine with the prepared specimen Fig 7 and tested specimen at Fig 8 .

The following observation are made by the tensile strength making its suitability to the engineering applications, as the addition of the fiber pandalus to the material the tensile strength of the material have shown consecutive increase and thereby attaining the maximum tensile strength of $12.53 \mathrm{MPa}$ and the minimum to the $20 \%$ addition of the fiber showing $8.66 \mathrm{MPa}$, this is due cause of the modulus of elasticity being increased by the addition of the volume fraction of the fiber, the fibers being promoting the elongation strength of the matrix , since the addition of the elongation depends on the amount of the fiber, in the combination of the matrix and fibers considered for our study the Maximum elongation of the fiber to $20 \%$ with $6.43 \%$ elongations. This suggest to use the minimum fiber quantity for maximum elongation. It is apprehended that the hydrophilic nature of the fiber is compatible to its application of the hydrophobic polymeric matrix and usually form an aggregate matrix. The aggregate formation leads influence towards the strength in terms of elongation factor and strain to elongation. The tensile strength and modulus increases within the tested increased weight ratio of the fiber specimen. Which makes its evident that the fiber concentration plays a vital role of making the matrix aggregation. Fig 9. Designates the comparison of 1, 2, 3 fiber with $20 \%, 30 \%, 40 \%$ mass fraction of fiber with both $\%$ of elongation and tensile strengths. Table 2 the Tensile Graph by the UTS is evidencing steep curve making the aspect of the limited elasticity.
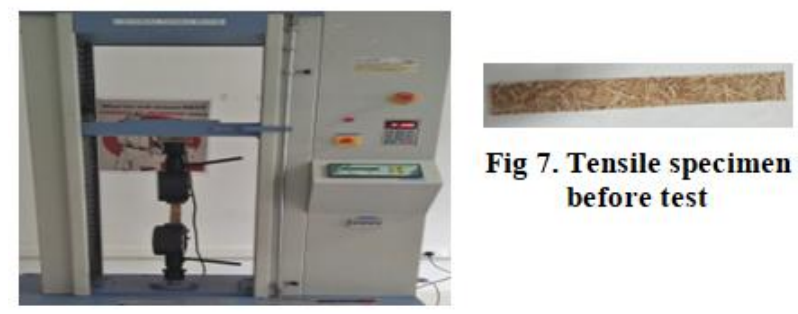

Fig 7. Tensile specimen before test

Fig 6. Universal tensile testing machine

Fig 8. Tensile specimen after test
Published By:

Blue Eyes Intelligence Engineering \& Sciences Publication 
Table II: Graphs and corresponding values of Tensile test

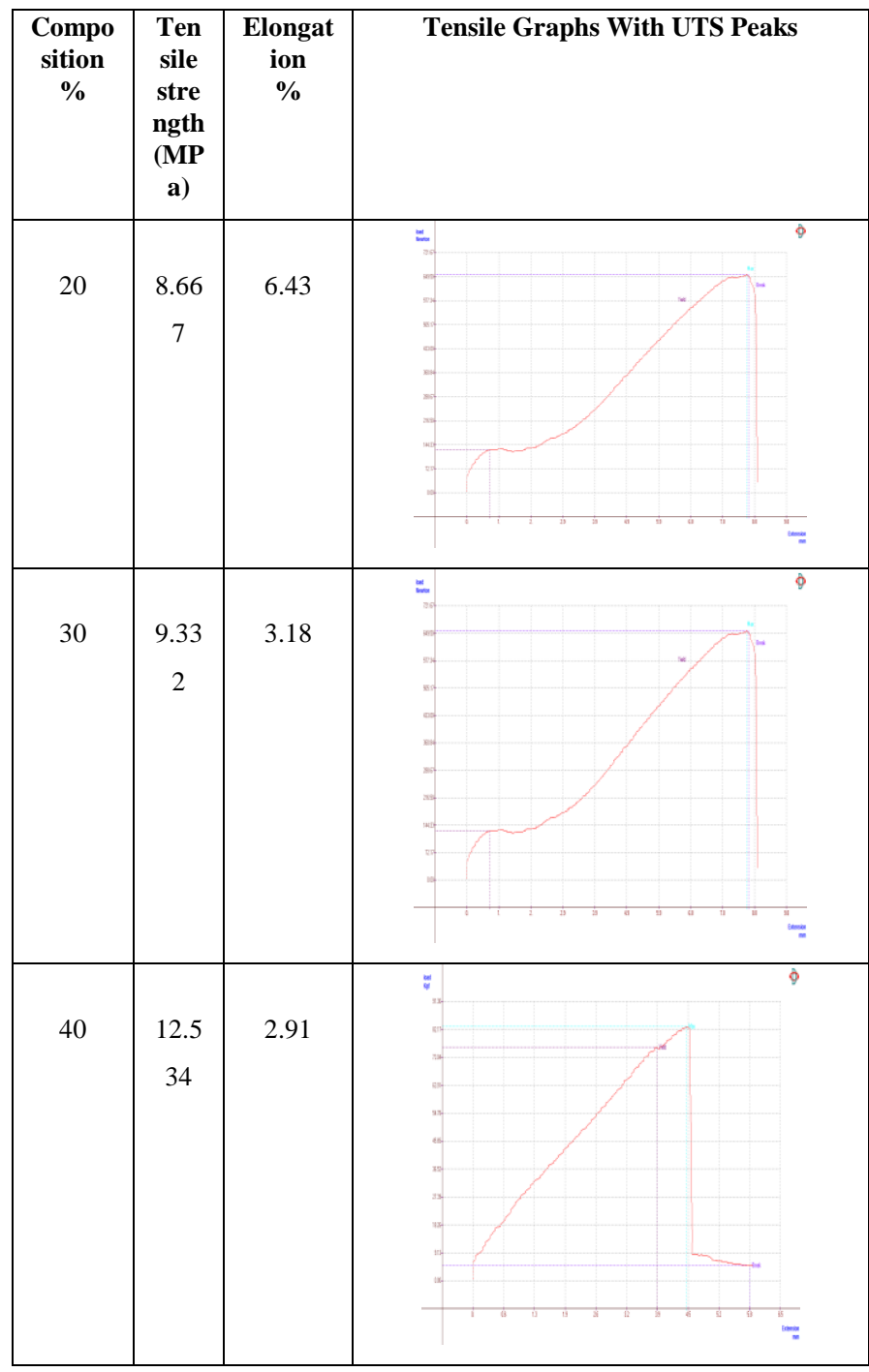

TENSILE TEST

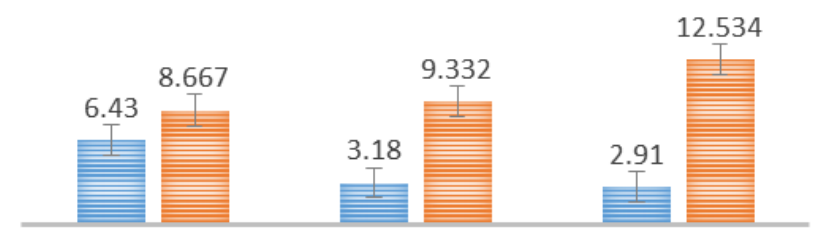

2

3

$\%$ of Composititon of Fibre

= $\%$ Elongation 플 Tensile Strength (MPa)

\section{B. Impact Test}

The impact test is nomenclature to enumerate the energy associated with the break of specimen which is absorbed by the specimen while breakage. The un-notched lzod impact test is conducted to study the impact energy according to the ASTM D256. The un-notched specimens are cut in to require size and kept in a position as simply supported beam to swing up the pendulum, to break the specimen making the specimen to absorb the energy. The tested specimen values have been tabulated in Table 3 . The impact energy $(\mathrm{J})$ is calculated from the dial gauge, which is being associated with the machine inherited. Nine samples are taken separately for both the base treated and untreated specimens and the results are analyzed and tabulated. The maximum energy absorbed was obtained by the $40 \%$ weight of fiber and the minimum energy absorption was obtained $20 \%$ weight which defines as the amount of the fiber content increases leading to the increase of the energy absorbed since the impact energy absorption is transferred to the varied amount of the fiber by mass. The breakage energy of the substance with the modulus were corporate to breakage spreading along the specimen. The specimen with less fiber have significantly failed to enunciate the higher order of energy and have failed tremendously due cause of the low energy distribution to the factor of the matrix contents. Whereby the inclusion of the fiber to the volume fraction shows the diversification of the impact along the volume of the fiber making the specimen as a whole to absorb the maximum energy.

Table III. Calculated results from the testing

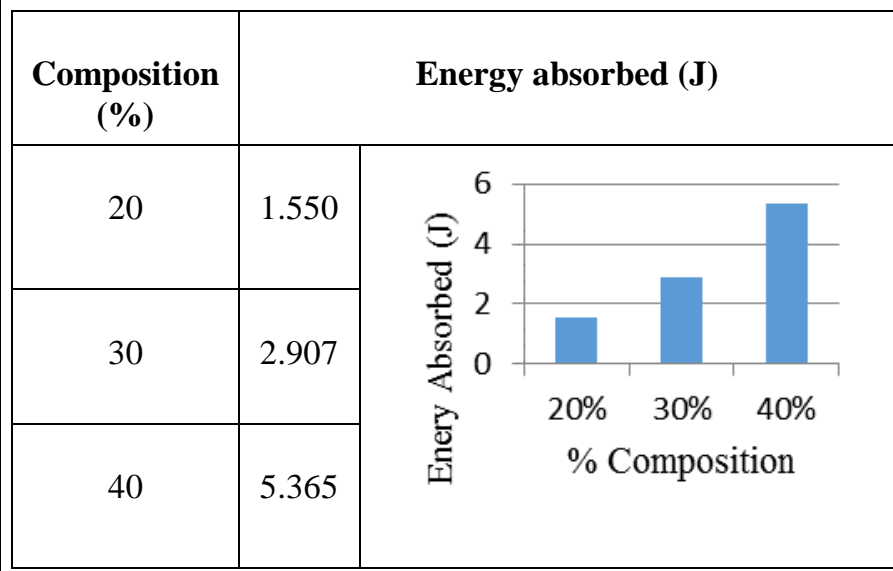

\section{CONCLUSION}

To conclude the following observations were made in the investing of pandanus odorifier fiber sheath with all layering sequences: Mechanical properties and chemical properties of the newly identified composite reinforcement, the pandanus odorifier fiber, are found to be having a considerable value. The composites with various fiber lengths and fiber weight percentage where analyzed. The analysis resulted in the identification of the significant increase in the mechanical properties such as the tensile strength as the increase of the fiber content and the decreased $\%$ of elongation. Though the dependency is assimilated by the increase of ultimate tensile strength and impact energy in increase of the fiber content and decrease of the \% elongation with increase of the fiber contents.

\section{REFERENCES}

1. Abhishek K. Pathak, Munu Borah, Ashish Gupta, T. Yokozeki, Sanjay R. Dhakate (2016)." Improved mechanical properties of carbon fiber/grapheme oxide-epoxy hybrid composites" Composite Science and Technology, pp. 28-38.

2. Alireza Khoddamzadeh, Rong Liu, Ming Liang and Qi Yang (2014) "Wear resistant carbon fiber reinforced Stellite alloy composites", Materials and Design. 


\section{Experimental Examination of Mechanical Analysis on Pandanus Odorifer Fiber Reinforced Polymer Composites}

3. Arpitha.G.R and B.Yogesha (2017). "An Overview on Mechanical Property Evaluation of Natural Fiber Reinforced Polymers", Materials Today Proceeding, Pages 2755-2760

4. Dimo Hristozov, Laura Wrobliewski, Pedram Sadeghian (2015). "Long-termtensile properties of natural fiber-reinforced polymer composites: comparison of flax and glass fibers"

5. Fabrizio Sarasini, Jacopo Tirillo and Maria Carolina Seghini (2017). Influence of thermal conditioning on tensile behavior of single basalt fibers.

6. Fiore.V, T. Scalici, G. Di Bella and A. Valenza (2014). "A review on basalt fiber and its composites"; Composite Part B, pp. 74-94

7. Guilherme Piovezan Otto, Murilo Pereira Moisés, Gizilene Carvalho, Andrelson Wellington Rinaldi, Juliana Carla Garcia, Eduardo Radovanovic, Silvia Luciana Fávaro(2016). Mechanical properties of a polyurethane hybrid composite with natural fiber.

8. . Hemath Kumar.V, H. Babu Visihwanath, Rajesh Purohit, Pramod Sahu and R. S. Rana (2016). Investigations on Mechanical Properties Of Glass And Sugarcane Fiber Polymer Matrix Composite

9. Herrera-Franco.P.J. and A. Valadez-Gonzalez (2014). "Mechanical properties of continuous natural fiber-reinforced polymer composites", international Journal of Polymer science.pp.15

10. Igor M. De Rosa, Carlo Santulli and Fabrizio Sarasini (2009) Acoustic emission for monitoring the mechanical behavior of natural fiber composites", Composite Part A.

11. Kabir, H. Wang, K.T. Lau and F. Cardona (2012). Chemical treatments on plant-based natural fiber reinforced polymer composites", Composite Part B.

12. Ku.H, H. Wang, N. Pattarachaiyakoop and M. Trada (2011). A review on tensile properties of natural fiber reinforced polymer composites, USQ Prints

13. Kin-tak Lau, Pui-yan Hung, Min-Hao Zhuc and David Hui (2017). Properties of natural fiber composites for structural engineering applications",Composite Part B.

14. Liu Lei, LiWeiwei, Tang Yiping, Shen Bin, HuWenbin(2009). Friction and wear properties of short carbon fiber reinforced aluminum matrix composites, CNKI.

15. Nele Defoirdt,, Subhankar Biswas, Linde De Vriese, Le Quan Ngoc Tran, Joris Van Acke, Qumrul Ahsan, Larissa Gorbatikh, Aart Van Vuure and Ignaas Verpoest(2010). Assessment of the tensile properties of coir, bamboo and jute fiber" Procedia Engineering. Pp.933-939

\section{AUTHORS PROFILE}

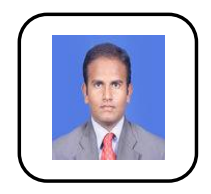

Jothiraj Palaniappan has completed his bachelor's degree in the department of Mechanical Engineering under Anna University with First rank and gold medal, proceeded with the degree of masters under the Manufacturing Engineering with First Rank and Gold medal. He is being nominated and selected as the Mentor for change under the NITI-Ayog, Govt. of India for AIM. Has published two papers in peer reviewed journals. Active member in the IAEng. Research interest being inclined towards the advanced materials as shape memory alloys and phase changing materials

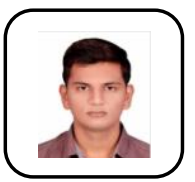

Vignesh $\mathbf{S}$ has graduated in the field of Mechanical Engineering from Anna University in 2013. He completed his post-graduation in Manufacturing Engineering from Anna University in 2016. His research area of interests are casting of non-ferrous alloys, development of polymer composites and mechanical behavior of materials. Presently he is working with Kalasalingam Academy of Research and Education as an Assistant professor in the department of Mechanical Engineering

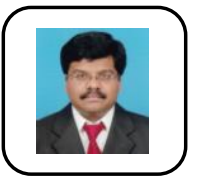

Winowlin Jappes J $\mathbf{T}$ graduated in 1997 from Manonmaniam Sunderanar University, India in Mechanical Engineering. In 1999, he has completed his masters in Production Engineering from Annamalai University. He completed his Ph.D degree in 2004 in the area of Composite Deposition at Indian Institute of Technology Madras, Chennai. He has completed three DST funded research projects and published more than 125 research articles which includes 65 International Journal papers. Currently, he is working as Senior Professor in Kalasalingam
University, India. His research interests includes high performance composite materials, machining of hard materials, optimization techniques, etc. At present, he is working as Professor and Dean, School of Automotive and Mechanical Engineering, Kalasalingam Academy of Research and Education, India.

Membership, achievements, with photo that will be maximum 200-400 words. 